\title{
In vitro Sterilization Protocol for Establishment of Litchi (Litchi chinensis Sonn) cv. Purbi
}

\author{
Neha Nischal, Hidayatullah Mir, Shaheena Parveen*, Shashi Prakash, \\ Ruby Rani and Sanjay Sahay
}

Department of Horticulture (Fruit \& Fruit Technology), Bihar Agricultural University, Bhagalpur, 813210, Bihar, India

*Corresponding author

\section{A B S T R A C T}

\begin{tabular}{l} 
K e y w o r d s \\
Litchi, \\
$\begin{array}{l}\text { Micropropagation, } \\
\text { NaOCl, } \mathrm{HgCl}_{2}, \\
\text { Mortality }\end{array}$ \\
\hline Article Info \\
\hline $\begin{array}{l}\text { Accepted: } \\
\text { 05 February } 2020 \\
\text { Available Online: } \\
\text { 10 March } 2020\end{array}$ \\
\hline
\end{tabular}

\section{Introduction}

Litchi (Litchi chinensis Sonn.) is one of the most popular subtropical fruits highly prized for its luscious white arils and has been rightly called as "Queen of fruits". It requires highly specific climate which directly affects its quality characters like shape, size, texture, and nutritive value. It belongs to the
Sapindaceae or soapberry family and sub family Nepheleae which comprises not less than 150 genera and 2000 species. It is grown as a major commercial crop in China, Taiwan, Vietnam, Thailand, India, Madagascar, South Africa and Reunion Islands and to a limited extent in Australia, New Zealand, Indonesia, Mauritius, Israel, Spain, the U.S and Mexico. China has litchi map of the world both, in 
terms of production and productivity. Conventionally litchi is propagated by vegetative means mainly through air layering or marcottage. Although various means to increase the efficiency of this method have been tried such as, use of younger branches, small earth balls and 1,4-indole-3-butyric acid (IBA), the process is still slow and inefficient. Hence, for large scale production of elite litchi clones, micropropagation can be used as a potential alternative to the vegetative means of reproduction. However, till date litchi has been proved to be a difficult material to be propagated using in vitro culture.

Plant tissue culture is a system of growing plant cells, tissue or organs, that have been separated from the mother plant (called explants) in artificial medium under aseptic condition (Omamor et al., 2007). Even though aseptic conditions are maintained, plant cultures may not stay aseptic in in vitro. The in vitro culture of any cell, organ and tissue can be contaminated basically from 4 types of sources. These sources are the plant (internal as well as external), the nutrient medium (insufficiently sterilized), the air, and the research worker (improper sterile techniques) (Pierik, 1994; Urbi and Zainuddin, 2015). Out of these, contamination resulting from microorganisms already present in the explant is a major challenge to establishment, initiation and maintenance of aseptic in vitro cultures.

The plants when grown under field conditions often get contaminated with a lot of soil and air borne pathogens and it therefore necessitates a thorough and effective sterilization procedure of the explants before culturing. The aim of this study was to investigate and identify the most effective sterilization technique for nodal segment and leaf explants of Litchi chinenesis obtained from the field.

\section{Materials and Methods}

Two sterilizing agents or disinfectants namely $\mathrm{NaOCl}$ and $\mathrm{HgCl}_{2}$, with different concentrations and various exposure time were used to surface sterilize the explants collected from the field. Litchi cultivar Purbi grown at Horticulture Garden of Bihar Agricultural College, Sabour was selected for the present investigation as source of explants. For the in vitro establishment, the required plant material used was leaf and nodal segment. Young shoot branches were cut from the healthy and disease free plants of selected genotype of litchi. They were brought to the laboratory and nodal segments containing axillary bud were cut out using scalpel and forceps, of about 1-2 cm length. Whereas, the young leaves excised in the form of $1 \mathrm{~cm} \times 1 \mathrm{~cm}$ were also collected as explants. Firstly, the prepared explants in suitable sizes were washed in running tap water 4-5 times. The washed explants were then washed in a solution containing 2- 3 drops detergent (tween -20) and 1-2 ml dettol for about 10 minutes. Thereafter explants were washed 2-3 times with sterilized water. The cleaned out nodal segment and leaf explant were then dipped in $0.2 \%$ bavistin solution for 50 minutes and 30 minutes respectively to control the fungal contamination. The nodal segments were then pretreated in a solution of $0.4 \%$ ascorbic acid for 40-50 minutes and leaves in $0.1 \%$ ascorbic acid solution for an hour in a beaker. This pretreatment with ascorbic acid was done to control phenolic exudation from the wounded parts. It also resulted in reduced microbial contamination. The pretreated explants were washed at least 3 times with sterile distilled water under laminar air flow. For surface sterilization these pretreated nodal explants were then treated with $0.1 \%$ and $0.2 \% \mathrm{HgCl}_{2}$ for 1,2,3,4 and 5 minutes and $1.0 \% \mathrm{NaOCl}$ for 2, 4, 6, 8 and 10 min while treatment of $\mathrm{HgCl}_{2}$ for $0.25,0.5,0.75,1.0,1.25$, and 1.5 minutes 
and $\mathrm{NaOCl}$ for 1, 2, 3, 4, 5 and 6 minutes was given to leaf explants.

\section{Results and Discussion}

The efficiency of the surface sterilants was evaluated based on the number of live aseptic cultures.

\section{Effect of surface sterilants on nodal segment explants}

$100 \%$ contamination was observed when no sterilant treatment was given. The contamination percent reduced with the increase of concentration and time duration of $\mathrm{HgCl}_{2}$. Minimum contamination of 21.4 $(27.5 \pm 0.40) \%$ was recorded when $0.2 \%$ $\mathrm{HgCl}_{2}$ treatment was given for 5 mins. Although this treatment decreased contamination, but at the same time also caused maximum mortality $41.2(39.9 \pm 0.65)$ $\%$ as compared to all other treatments. However, $0.2 \% \mathrm{HgCl}_{2}$ for $3 \mathrm{~min}$ resulted in maximum survival $69.5(56.5 \pm 1.19) \%$ of nodal segment explants with mortality of only $5.7(13.8 \pm 0.18) \%$ explants and contamination of $29.8(33.1 \pm 0.51) \%$ explants. Sodium hypochlorite on the other hand although reduced the mortality rate but the efficiency to control contamination was much lower than various treatments of $\mathrm{HgCl}_{2}$. Although per cent contamination was seen negatively correlated with the concentration and time of exposure of the sterilants, the survival percent significantly reduced. Overall, $\mathrm{HgCl}_{2}(0.2) \%$ for 3 min treatment was found to be the most effective that resulted in maximum per cent survival $(56.5 \pm 1.19) \%$, low percent mortality $(13.8 \pm 0.18) \%$ and low per cent contamination $(33.1 \pm 0.51) \%$.

Table.4.1 Effect of different treatment and duration of surface sterilants on nodal explants of litchi cv. Purbi

\begin{tabular}{|c|c|c|c|c|}
\hline Treatment & Treatment and duration & $\begin{array}{l}\text { Per cent } \\
\text { contamination }\end{array}$ & $\begin{array}{l}\text { Per } \\
\text { mortality }\end{array}$ & Per cent survival \\
\hline T0 & Control & $100.0(90.0 \pm 0.00)$ & $0.0(0.0 \pm 0.00)$ & $0.0(0.0 \pm 0.00)$ \\
\hline T1 & $\mathrm{HgCl}_{2}(0.1 \%)$ for $1 \mathrm{~min}$ & $98.2(83.0 \pm 2.25)$ & $1.5(6.9 \pm 0.08)$ & $4.6(12.4 \pm 0.16)$ \\
\hline $\mathbf{T 2}$ & $\mathrm{HgCl}_{2}(0.1 \%)$ for $2 \mathrm{~min}$ & $94.6(76.5 \pm 0.37)$ & $2.2(8.5 \pm 0.11)$ & $8.2(16.6 \pm 0.24)$ \\
\hline T3 & $\mathrm{HgCl}_{2}(0.1 \%)$ for $3 \mathrm{~min}$ & $90.9(72.8 \pm 2.59)$ & $2.8(9.7 \pm 0.15)$ & $11.2(19.6 \pm 0.29)$ \\
\hline T4 & $\mathrm{HgCl}_{2}(0.1 \%)$ for $4 \mathrm{~min}$ & $88.8(70.7 \pm 2.28)$ & $3.4(10.6 \pm 0.14)$ & $12.8(20.9 \pm 0.30)$ \\
\hline T5 & $\mathrm{HgCl}_{2}(0.1 \%)$ for $5 \mathrm{~min}$ & $82.4(65.3 \pm 1.73)$ & $5.4(13.4 \pm 0.18)$ & $17.2(24.5 \pm 0.35)$ \\
\hline T6 & $\mathrm{HgCl}_{2}(0.2 \%)$ for $1 \mathrm{~min}$ & $58.4(49.8 \pm 0.94)$ & $4.4(12.1 \pm 0.16)$ & $42.2(40.5 \pm 0.67)$ \\
\hline $\mathbf{T 7}$ & $\mathrm{HgCl}_{2}(0.2 \%)$ for $2 \mathrm{~min}$ & $38.1(38.1 \pm 0.61)$ & $5.6(13.6 \pm 0.18)$ & $61.3(51.5 \pm 0.98)$ \\
\hline T8 & $\mathrm{HgCl}_{2}(0.2 \%)$ for $3 \mathrm{~min}$ & $29.8(33.1 \pm 0.51)$ & $5.7(13.8 \pm 0.18)$ & $69.5(56.5 \pm 1.19)$ \\
\hline T9 & $\mathrm{HgCl}_{2}(0.2 \%)$ for $4 \mathrm{~min}$ & $27.8(31.8 \pm 0.50)$ & $19.0(25.8 \pm 0.38)$ & $58.2(49.7 \pm 0.92)$ \\
\hline T10 & $\mathrm{HgCl}_{2}(0.2 \%)$ for $5 \mathrm{~min}$ & $21.4(27.5 \pm 0.40)$ & $41.2(39.9 \pm 0.65)$ & $42.4(40.6 \pm 0.67)$ \\
\hline T11 & $\mathrm{NaOCl}(1 \%)$ for $2 \mathrm{~min}$ & $89.7(71.5 \pm 2.36)$ & $7.2(15.6 \pm 0.22)$ & $8.1(16.5 \pm 0.24)$ \\
\hline T12 & $\mathrm{NaOCl}(1 \%)$ for $4 \mathrm{~min}$ & $84.4(66.8 \pm 1.84)$ & $8.6(17.0 \pm 0.24)$ & $12.0(20.2 \pm 0.28)$ \\
\hline T13 & $\mathrm{NaOCl}(1 \%)$ for $6 \mathrm{~min}$ & $76.0(60.7 \pm 1.40)$ & $11.7(19.9 \pm 0.28)$ & $17.3(24.6 \pm 0.37)$ \\
\hline T14 & $\mathrm{NaOCl}(1 \%)$ for $8 \mathrm{~min}$ & $69.7(56.6 \pm 1.19)$ & $11.8(20.0 \pm 0.28)$ & $23.5(29.0 \pm 0.43)$ \\
\hline T15 & $\mathrm{NaOCl}(1 \%)$ for $10 \mathrm{~min}$ & $63.4(52.8 \pm 1.03)$ & $12.8(20.9 \pm 0.30)$ & $28.8(32.4 \pm 0.49)$ \\
\hline C.D & & 4.30 & 0.76 & 1.65 \\
\hline S.E(m) & & 1.49 & 0.26 & 0.57 \\
\hline
\end{tabular}


Table.2 Effect of different treatment duration of sterilizing agents on leaf explants

\begin{tabular}{|c|c|c|c|c|}
\hline Treatment & Treatment and duration & $\begin{array}{l}\text { Per cent } \\
\text { contamination }\end{array}$ & $\begin{array}{l}\text { Per } \\
\text { mortality }\end{array}$ & Per cent survival \\
\hline $\mathbf{T}_{\mathbf{0}}$ & Control & $100.0(89.4 \pm 0.62)$ & $0.0(0.0 \pm 0.00)$ & $0.0(0.0 \pm 0.00)$ \\
\hline $\mathbf{T}_{1}$ & $\mathrm{HgCl}_{2}(0.1 \%)$ for $0.25 \mathrm{~min}$ & $84.6(67.0 \pm 1.87)$ & $3.8(11.2 \pm 0.17)$ & $16.6(24.0 \pm 0.36)$ \\
\hline $\mathbf{T}_{2}$ & $\mathrm{HgCl}_{2}(0.1 \%)$ for $0.5 \mathrm{~min}$ & $52.9(46.6 \pm 0.83)$ & $4.1(11.7 \pm 0.17)$ & $48.0(43.8 \pm 0.76)$ \\
\hline $\mathbf{T}_{3}$ & $\mathrm{HgCl}_{2}(0.1 \%)$ for $0.75 \mathrm{~min}$ & $47.0(43.3 \pm 0.75)$ & $5.0(12.9 \pm 0.19)$ & $52.9(46.6 \pm 0.83)$ \\
\hline $\mathbf{T}_{4}$ & $\mathrm{HgCl}_{2}(0.1 \%)$ for $1.0 \mathrm{~min}$ & $33.8(35.5 \pm 0.56)$ & $5.9(14.0 \pm 0.21)$ & $65.3(53.9 \pm 1.08)$ \\
\hline $\mathbf{T}_{5}$ & $\mathrm{HgCl}_{2}(0.1 \%)$ for $1.25 \mathrm{~min}$ & $30.2(33.3 \pm 0.52)$ & $16.1(23.6 \pm 0.34)$ & $58.7(50.0 \pm 0.94)$ \\
\hline $\mathbf{T}_{6}$ & $\mathrm{HgCl}_{2}(0.1 \%)$ for $1.5 \mathrm{~min}$ & $25.7(30.5 \pm 0.47)$ & $29.2(32.7 \pm 0.51)$ & $50.1(45.0 \pm 0.79)$ \\
\hline $\mathbf{T}_{7}$ & $\mathrm{NaOCl}(1 \%)$ for $1 \mathrm{~min}$ & $95.8(78.9 \pm 3.83)$ & $2.5(9.1 \pm 0.11)$ & $6.7(15.0 \pm 0.20)$ \\
\hline $\mathbf{T}_{8}$ & $\mathrm{NaOCl}(1 \%)$ for $2 \mathrm{~min}$ & $84.7(67.1 \pm 1.88)$ & $2.8(9.7 \pm 0.15)$ & $17.4(24.7 \pm 0.37)$ \\
\hline $\mathbf{T}_{9}$ & $\mathrm{NaOCl}(1 \%)$ for $3 \mathrm{~min}$ & $71.9(58.0 \pm 1.27)$ & $4.4(12.1 \pm 0.16)$ & $28.7(32.3 \pm 0.49)$ \\
\hline $\mathbf{T}_{10}$ & $\mathrm{NaOCl}(1 \%)$ for $4 \mathrm{~min}$ & $63.1(52.6 \pm 1.03)$ & $5.7(13.8 \pm 0.18)$ & $36.2(37.0 \pm 0.60)$ \\
\hline $\mathbf{T}_{11}$ & $\mathrm{NaOCl}(1 \%)$ for $5 \mathrm{~min}$ & $55.3(48.0 \pm 0.88)$ & $6.0(14.2 \pm 0.21)$ & $43.7(41.3 \pm 0.70)$ \\
\hline$T_{12}$ & $\mathrm{NaOCl}(1 \%)$ for $6 \mathrm{~min}$ & $48.1(43.9 \pm 0.76)$ & $14.4(22.3 \pm 0.33)$ & $42.5(40.7 \pm 0.69)$ \\
\hline C.D & & 4.30 & 0.70 & 1.95 \\
\hline S.E(m) & & 1.47 & 0.24 & 0.67 \\
\hline
\end{tabular}

\section{Effect of surface sterilants on leaf explants}

As the concentration and duration of treatments were increased contamination decreased but it also led to the aggravation in mortality rate (table 2). $100 \%$ explants were contaminated in control conditions. The contamination percent of explants decreased with increasing time of exposure for both the sterilants. But with the increasing time duration the mortality percent also increased while the survival percent decreased. Although treatment T6 showed least contamination of $25.7(30.5 \pm 0.47) \%$ but it also showed a mortality of $29.2(32.7 \pm 0.51) \%$ which was highest compared to other treatments. $\mathrm{T}_{4}$ was found to be the most effective treatment resulting in highest per cent survival $(53.9 \pm 1.08) \%$, low per cent mortality $(14.0 \pm 0.21) \%$ and low per cent contamination $(35.5 \pm 0.56) \%$.

The use of field grown plants as direct sources of explants for the production of 'clean' in vitro plantlets, presents a major challenge (Webster et al., 2003). This is because the surface of field grown plants carries a wide range of microorganisms (Daud et al., 2012). Nearly all fungal and yeast and some bacterial species are severe hazards in vitro because they grow well on plant tissue culture media thus increasing the competition for nutrients and kill plants by reducing the $\mathrm{pH}$ and the production of toxic metabolites (Leifert et al., 1991). So, surface sterilization is a must before transfer of explants to the culture media. In this experiment we concluded that exposure to lower concentration of sterilants, increased the contamination of explants, whereas exposure to higher concentrations for longer duration though reduced the contamination but also increased the mortality considerably for all the explants. This indicates the deleterious effect of the sterilants at higher concentrations. In this experiment $\mathrm{HgCl}_{2}$ was found to be better sterilizing agent than $\mathrm{NaOCl}$ for both the explants. The effectiveness of $\mathrm{HgCl}_{2}$ for surface sterilization of explants from woody plants has been reported by several workers such as Chandra et al., (2004) in mango, Zamir et al., (2004) in guava, Daud et al., (2012) in Aquilaria 
malaccensis and Parveen et al., (2019) in pineapple.

In conclusion, the results of the present study showed that among the two surface sterilizing agents tested, $\mathrm{HgCl} 2$ was better than $\mathrm{NaOCl}$ for both the explants i.e. nodal segments and leaves. Also it was found that although increasing the concentration and duration of exposure to sterilizing agents beyond certain limits reduced contamination but at the same time it also increased the mortality percent of the explants

\section{References}

Chandra, R., Padaria, J. C., and Srivastava, S. (2004). Factors influencing in vitro establishment of mango shoot buds. Indian Journal of Plant Physiology, 9, 136-144.

Daud, N. H., Jayaraman, S., and Mohamed, R. (2012). Methods Paper: An improved surface sterilization technique for introducing leaf, nodal and seed explants of Aquilaria malaccensis from field sources into tissue culture. As. Pac. J. Mol. Biol. and Biotech, 2, 55-58.

Leifert, C., Ritchie, J., and Waites, W.M. (1991). Contaminants of plant tissue and cell cultures. World J Microbiol Biotechnol 7:452-469.

Omamor, I.B., Asemota, A.O., Eke, C.R. and Ezia, E.I. (2007). Fungal contaminants of the oil palm tissue culture in Nigerian Institute for Oil Palm Research (NIFOR). African Journal of
Biotechnology 2(10): 534-537.

Parveen, S., Mir, H., Ranjan, T., Pal, A., and Kundu, M. (2019). Effect of Surface Sterilants on in vitro Establishment of Pineapple (Ananas comosus (L.) Merill.) cv. Kew. Current Journal of Applied Science and Technology, 33(2), $1-6$

Pierik, R. L. M. (1997). In Vitro Culture of Higher Plants. Springer Science and Business Media. 89-94.

Urbi, Z., and Zainuddin, Z. (2015). Standardization of surface sterilization protocol of field grown Stevia rebaudiana prior to in vitro clonal propagation. Journal Teknologi, 77(24), 141-6.

Webster, S., Mitchell, S.A. and Ahmad, M.H. (2003). A novel surface sterilization method for reducing fungal and bacterial contamination of field grown medicinal explants intended for in vitro culture. Proceedings of 17th SRC conference entitled 'Science and Technology for Economic Development: Technology Driven Agriculture and Agro-Processing' SRC, Jamaica.

http://www.kitchenculturekit.com/surfa ceSterilizationMitchell2003. Pdf

Zamir, R., Shah, S. T., Ali, N., Khattak, G. S. S., \& Muhammad, T. (2004). Studies on in vitro surface sterilization and antioxidants on guava shoot tips and nodal explants. Pak. J. Biotech, 1(2), $12-16$.

\section{How to cite this article:}

Neha Nischal, Hidayatullah Mir, Shaheena Parveen, Shashi Prakash, Ruby Rani and Sanjay Sahay. 2020. In vitro Sterilization Protocol for Establishment of Litchi (Litchi chinensis Sonn) cv. Purbi. Int.J.Curr.Microbiol.App.Sci. 9(03): 831-835. doi: https://doi.org/10.20546/ijcmas.2020.903.097 